\title{
Optimization of HIB Value Combination of Tween 60 and Span 80 on Cream Formulation of Ethanol Extract of Green Tea Leaves (Camellia Sinensis L.)
}

\author{
Fransiska Lisa Anindya Putri*, Akhmad Kharis Nugroho, Erna Prawita Setyowati \\ Faculty of Pharmacy, Universitas Gadjah Mada, Yogyakarta, Indonesia
}

\begin{abstract}
Green tea (Camellia sinensis L.) is known to have ability to protect skin against free radicals. This is supported by polyphenol compound catechin. This research aims to determine the optimum HydrophilicLipophilic Balance (HLB) value of Tween 60 and Span 80 compositions on the optimum cream formula of ethanol extract of green tea leaves. Tea leaves are extracted by macerating using $70 \%$ ethanol. Catechin in extract is known from Thin Layer Chromatography (TLC) test with silica gel $60 \mathrm{~F}_{254}$ as stationary phase and ethyl acetate:aquadest:formic acid (18:1:1 v/v) as mobile phase. Antioxidant activity is determined by 2,2Diphenyl-1-picryhydrazyl (DPPH) method and value of Inhibition Concentration 50\% ( $\mathrm{IC}_{50}$ ) is then calculated. Formula optimization using Design Expert® version 7.1.5 (DX 7) software, Simplex Lattice Design (SLD) method with two components Tween 60 and Span 80. Cream is characterized according to physical properties organoleptic, homogeneity, viscosity, $\mathrm{pH}$, spreadability, adhesiveness, and cream type. The optimum formula obtained is then tested for physical stability for 4 weeks at room temperature $\left(28 \pm 2^{\circ} \mathrm{C}\right)$ and data are statistically analyzed using one-way ANOVA. The extract contains catechin proved with Retention factor (Rf) value 0.8 and has antioxidant activity with $\mathrm{IC}_{50}$ value $56.35 \mathrm{ppm} .6 .4 \%$ Tween 60 and $3.6 \%$ Span 80 result an optimum HLB value 11.1. It has viscosity $2897.50 \pm 35.94 \mathrm{mPa} . \mathrm{s}$, spreadability $18.44 \pm 0.06 \mathrm{~cm}^{2}$, adhesiveness $0.85 \pm 0.05$ seconds, and pH $4.530 \pm 0.002$. Statistical test shows that the cream is significantly altered at $\mathrm{pH}$, but does not significantly change in viscosity, spreadability, and adhesiveness after being stored for 4 weeks.
\end{abstract}

Key words: optimization; HLB; Tween 60; Span 80

\section{INTRODUCTION}

Cosmetics are a necessity that absolutely need to be fulfilled nowadays. Utilization of natural or herbal ingredients as active ingredients in cosmetic preparations is now getting more common. The possibility of negative reactions on skin due to mixtures of chemical compounds causes consumers to switch to herbal cosmetic products (Singh et al., 2011).

One of the plants widely known by the public is tea. Various studies show that green tea is beneficial for preventing cancer, osteoporosis, cardiovascular, Parkinson's disease and Alzheimer's, as well as lowering blood pressure. Meanwhile, for beauty care, green tea is used to slim down, prevent early aging, eliminate bad breath and get rid of acne (Soraya, 2007).

Green tea has antioxidant properties. These properties lie in the presence of polyphenols in the form of catechins. Antioxidants of green tea could ward off free radicals and stop the proliferation of cancer cells. Free radicals could damage DNA,

\footnotetext{
*Corresponding author : Fransiska Lisa Anindya Putri

Email : fransiskaanindya@gmail.com
}

which could result in faster aging process (Chacko et al., 2010).

In this study, ethanol extracts of green tea leaves are formulated into cream. Creams are semisolid preparations, in the form of emulsions that contain no less than $60 \%$ of water and are intended for external use (Ministry of Health of the Republic of Indonesia, 1979). Creams contain emulsions between oil phase and water phase and are stabilized by an emulsifier. One type of emulsifier is non-ionic surfactants. Non-ionics surfactants are non-electrolytes and therefore, they are not sensitive to the changes in $\mathrm{pH}$ of medium. They are more neutral because they are not ionized as is the case with ionic surfactants (Mahato, 2007). Therefore, these surfactants are more stable in both acidic and alkaline conditions.

The non-ionic surfactants used is a combination of Tween 60 and Span 80. Tween 60 is a water-soluble emulsifier that has a HLB value of 14.9 and thus, it could form $\mathrm{O} / \mathrm{W}$ emulsions. Meanwhile, lipophilicity characteristics of Span 80 are more dominant, and this surfactant has a HLB value of 4.3 so that it forms W/O emulsions (Rowe et al., 2009). HLB value difference between these two surfactants could result in differences in 
physical characteristics and physical stabilityof a cream. The selected cream produced from the combination of these two surfactants is the $0 / \mathrm{W}$ type so that the HLB value is in the range of 8-18 (Allen et al., 2004).

Based on those reasons, this research aims to optimize the HLB value in cream formulation of green tea leaves ethanol extract. The method used is Simplex Lattice Design with two components, namely Tween 60 and Span 80.

\section{METHODOLOGY \\ Tools and Ingredients}

Pollinator, kitchen pot, stainless steel frying pan, spatula, bleached calico fabrics, aluminum foil, extracts bottles, electric stove (Robusta $\AA$ ), silica gel $60 \mathrm{~F}_{254}$, capillary pipe, TLC chamber, weighing bottles, oven, desiccator without desiccant, analytical balance (Adventurer ${ }^{\mathrm{TM}}$ ), UV-Vis spectrophotometer, cuvette, micropipette (Gilson Pipetman, Germany), porcelain cups, water bath (Memmert $囚$ ), ultra turrax T25 (Janke \& Kunkel Ika $\AA$-Labortechnik), cream pots, glasswares (PYREX-Germany), Viscotester Brookfield, pHmeter (HANNA ${ }^{\mathrm{TM}}$ ), laboratory glass plates (used for homogeneity test), spreadability test apparatus (Pharmaceutical Technology Laboratory, Faculty of Pharmacy UGM), adhesive testing equipment (Pharmaceutical Technology Laboratory, Faculty of Pharmacy UGM), object glasses, and stopwatch (Alba Digital Stopwatch).

Green tea leaves obtained from Desa Nglinggo, Pagerharjo, Samigaluh, Kulon Progo, DI Yogyakarta, ethanol 70\% (pharmaceutical grade), ethanol (pro analysis), DPPH (2,2-Diphenyl-1picrylhydrazyl) radicals, pure vitamin C, ethyl acetate (pro analysis), formic acid (pro analysis), ammonia, $\mathrm{FeCl}_{3}$ solution. The materials used for pharmaceutical grade formulation are Tween 60 , Span 80, liquid paraffin, white vaseline, cetyl alcohol, methylparaben, and distilled water.

\section{Work Procedures \\ Preparation of Dried Green Tea Leaves}

Green tea leaves were cut after they were cleaned from dirt with running water. After that, the leaves were heated in an oven at $55^{\circ} \mathrm{C}$ for $2-3$ days. Dried green tea leaves were then pollinated using a grinder. Finally, dried green tea powder was stored in a dark bottle.

\section{Preparation of Green Tea Leaves Ethanol Extract}

Extraction was carried out by maceration using a $70 \%$ ethanol solvent. One part of dried green tea powder was put into a maceration apparatus and then it was added with 10 parts of ethanol. The mixture was soaked in ethanol $70 \%$ for the first 6 hours while stirred occasionally, and then it was left to sit for 18 hours. Macerates were separated by filtration. This process was repeated at least twice with the same type and amount of solvent. All macerates were collected to be evaporated until thick extracts were obtained (Ministry of Health of the Republic of Indonesia, 2008). The obtained thick extracts were stored in a brown bottle. Yield of extracts is expressed according to equation (1):

$$
\text { Yield }(\% \mathrm{w} / \mathrm{w})=\frac{\text { thick extract weight }}{\text { simplicia powder weight }} \times 100 \%
$$

\section{Evaluation of Extract Quality}

Organoleptic Test

Observation on the color, smell, and texture of the extracts was conducted.

\section{Loss on Drying Determination}

Weighing bottle with constant weight were prepared (heated at $105^{\circ} \mathrm{C}$ for 30 minutes). Two grams of thick extracts were put into weighing bottles until it became a layer of 5-10 $\mathrm{mm}$. The bottle was opened and dried in an oven at $105^{\circ} \mathrm{C}$ for 5 hours. After the bottle was removed from the oven and was left to sit for 15 minutes, it was weighed again. The opened weighing bottle and the extracts were heated again for 30 minutes and weighed afterward (Ministry of Health of the Republic of Indonesia, 2008).

This process was repeated until constant weight was obtained and then the loss on drying was calculated. Loss on drying is expressed in equation (2):

Loss on Drying $=\frac{\text { initial weight }(\mathrm{g})-\text { final weight }(\mathrm{g})}{\text { initial weight }(\mathrm{g})} \times 100 \%$

\section{Thin Layer Chromatography Test}

One gram of green tea leaf ethanol extract was diluted in $10 \mathrm{~mL}$ of ethanol p.a. and later sonificated for 10 minutes. The elution length is 8 $\mathrm{cm}$. The mobile phase used was acetate:distilled water:formic acid (18:1:1 v/v), while the stationary phase used was silica gel $60 \mathrm{~F}_{254}$ that had been activated by heating in an oven at $30-40^{\circ} \mathrm{C}$ for 10 minutes.

After elution, the spots were evaporated with ammonia and observed with $\mathrm{UV}_{254}$ light, a pale blue color indicates the presence of catechins. Spots visualization with $\mathrm{FeCl}_{3}$ reagent (Robinson, 1995 in Rustanti et al., 2013). Rf value of catechin in the sample was then compared to the value in literature, which is 0.88 (Amarowicz, 2005 in Rustanti etal., 2013). Rf value is expressed 
Table I. Formula of Green Tea Leaves Ethanol Extract Cream

\begin{tabular}{lcccccccc}
\hline \multirow{2}{*}{ Materials (gram) } & \multicolumn{9}{c}{ Run } \\
\cline { 2 - 9 } & $\mathbf{R 1}$ & $\mathbf{R 2}$ & $\mathbf{R 3}$ & $\mathbf{R 4}$ & $\mathbf{R 5}$ & $\mathbf{R 6}$ & $\mathbf{R 7}$ & $\mathbf{R 8}$ \\
\hline Green tea extracts & 1 & 1 & 1 & 1 & 1 & 1 & 1 & 1 \\
Tween 60 & 0 & 5 & 2.5 & 10 & 0 & 10 & 7.5 & 5 \\
Span 80 & 10 & 5 & 7.5 & 0 & 10 & 0 & 2.5 & 5 \\
Liquid paraffin & 12.5 & 12.5 & 12.5 & 12.5 & 12.5 & 12.5 & 12.5 & 12.5 \\
White vaseline & 22.5 & 22.5 & 22.5 & 22.5 & 22.5 & 22.5 & 22.5 & 22.5 \\
Cetyl alcohol & 2 & 2 & 2 & 2 & 2 & 2 & 2 & 2 \\
Methylparaben & 0.15 & 0.15 & 0.15 & 0.15 & 0.15 & 0.15 & 0.15 & 0.15 \\
Aquadest & 51.85 & 51.85 & 51.85 & 51.85 & 51.85 & 51.85 & 51.85 & 51.85 \\
\hline
\end{tabular}

Table II. HLB value of Green Tea Leaves Ethanol Extract Cream

\begin{tabular}{ccccccccc}
\hline Run & R1 & R2 & R3 & R4 & R5 & R6 & R7 & R8 \\
\hline HLB & 4.3 & 9.6 & 6.9 & 14.9 & 4.3 & 14.9 & 12.2 & 9.6 \\
\hline
\end{tabular}

according to equation (3):

$$
\mathrm{Rf}=\frac{\text { length traveled by compound from original point }}{\text { length traveled by solvent from original point }}
$$

\section{Antioxidant Activity Test (DPPH method)}

Solutions Test Preparation

Preparation of $0.4 \mathrm{mM}$ DPPH solution, 15.7 $\mathrm{mg}$ of DPPH radical powder was put into a 100.0 $\mathrm{mL}$ volumetric flask and was added with ethanol p.a until the volume was exactly $100.0 \mathrm{~mL}$.

Preparation of green tea leaves extract solution, a standard extract solution of $1000 \mathrm{ppm}$ concentration was prepared, and then concentrations of $20,40,60,80$, and 100 ppm were prepared with a volume of $5.0 \mathrm{~mL}$ each.

Preparation of vitamin C solution, a 1000 ppm standard solution of vitamin $C$ was prepared, and then concentrations of 10, 15, 20, 25, and 30 ppm were made with a volume of $5.0 \mathrm{~mL}$ each.

Determination of $\lambda$ maximum for DPPH, 1.0 $\mathrm{mL}$ solution of $0.4 \mathrm{mM}$ DPPH was added with ethanol p.a. until the volume was exactly $5.0 \mathrm{~mL}$. After that, the mixture was vortexed and absorbance scanning was conducted using spectrophotometer at 30 minutes operating time with a wavelength range of 450-550 $\mathrm{nm}$ in order to obtain a description of its maximum absorbance.

Absorbance measurement of test compounds, a total of $500.0 \mu \mathrm{L}$ sample solutions (green tea extracts and vitamin $\mathrm{C}$ solutions) were respectively added with $1.0 \mathrm{~mL}$ solution of $0.4 \mathrm{mM}$ DPPH and ethanol p.a. until the volume was exactly $5.0 \mathrm{~mL}$. The mixture was vortexed and left to sit for 30 minutes. Then, its absorbance was read at $\lambda$ maximum. The blank used was ethanol p.a. This test was conducted with 2 replications. Antioxidant activity (AA) is measured through equation (4):

$$
\text { AA }(\%)=\frac{\text { Abs blank }- \text { Abs sample }}{\text { Abs blank }} x 100 \%
$$

\section{Formulation and Evaluation of Physical Properties of Cream}

The formula used refers to Dermatological Preparations of The Tropics (1991), with modifications to the addition of active and inactive substances. Formula optimization using SLD with two components by DX 7 software produced eight runs (Table I). The HLB values obtained (Table II).

All ingredients were weighed and grouped into oil or water phase. The oil phase consists of liquid paraffin, white vaseline, cetyl alcohol, and Span 80 heated over a water bath to $70^{\circ} \mathrm{C}$. The water phase consists of distilled water, Tween 60 , and methylparaben also heated to $70^{\circ} \mathrm{C}$. The oil phase was homogenized using ultra turrax. The water phase was then gradually added to the oil phase while both of them were still hot. The mixture was continuously stirred until it thickened and resembled a cream, and after the cream was formed it was left heated to $60^{\circ} \mathrm{C}$. Extracts that had been dissolved in distilled water were added into the cream and they were stirred until homogeneous. After that, the cream was put into a tightly closed container (pot).

The physical properties of the cream, which include organoleptic; homogeneity; viscosity; spreadability; adhesiveness; $\mathrm{pH}$; and cream type, were then tested.

\section{Optimal Formula Determination}

Optimal formula determination was conducted using SLD method in DX 7 software. The goal and importance of each quantified parameters of the physical properties of the cream i.e. 
Table III. Data of Viscosity, Spreadability, Adhesiveness, and pH of Eight Run Creams

\begin{tabular}{ccccc}
\hline Run & Viscosity (mPa.s) & Spreadability $\left(\mathbf{c m}^{2}\right)$ & Adhesiveness (seconds) & pH \\
\hline R1 & 6077.5 & 12.00 & 0.95 & 5.015 \\
R2 & 2062.5 & 18.51 & 0.91 & 5.063 \\
R3 & 3452.2 & 13.12 & 0.85 & 4.935 \\
R4 & 1582.5 & 24.28 & 0.83 & 4.145 \\
R5 & 6312.5 & 13.15 & 0.91 & 4.549 \\
R6 & 1757.5 & 18.40 & 0.95 & 4.419 \\
R7 & 2697.5 & 18.07 & 0.85 & 4.651 \\
R8 & 3215 & 19.89 & 0.68 & 4.721 \\
\hline
\end{tabular}

spreadability, adhesiveness, viscosity, and $\mathrm{pH}$ were determined. Based on the lower and upper limit (Table IV), the obtained optimal formula has a higher concentration of Tween 60 compared to that of Span 80. The mixed HLB value of concentration ratio between Tween 60 and Span 80 was then calculated using equation (5):

$\begin{array}{ll}\text { Tween } 60 \mathrm{~A} & =\mathrm{A} \% \times \text { HLB A } \\ \text { Span } 80 \mathrm{~B} & =\mathrm{B} \% \times \text { HLB B } \\ \text { Mixed HLB } & =\mathrm{A}+\mathrm{B}\end{array}$

\section{Optimal Formula Verification}

The production of optimal cream formula using the method and evaluated the physical properties of the same cream as in the eight run optimization. The test results are then compared with the predictive value of DX 7 software SLD method using statistical analysis of one sample ttest with a 95\% confidence level. The optimal formula verification is used to prove the validity of the SLD method by predicting the optimal formula.

\section{Physical Optimal Formula Stability Test}

The optimal cream formula obtained was then tested for physical stability at room temperature $\left(28 \pm 2^{\circ} \mathrm{C}\right)$ for 4 weeks to see if the optimal cream formula still had the same physical properties during storage. Tests conducted include organoleptic, homogeneity, spreadability, adhesiveness, viscosity, $\mathrm{pH}$, and cream type test. Tests are conducted every week for 4 weeks of storage.

\section{Method of Analysis}

Data is analyzed using IBM SPSS Statistics Version 24 software using the Shapiro-Wilk statistic test to see whether the data obtained is normally distributed or not. Data is normally distributed if it has a significance value $>0.05$. If the data are normally distributed, the data is analyzed by one sample t-test, whereas if the data is not normally distributed, the data is tested by Mann-Whitney. The confidence level used is $95 \%$.
To see the difference response of the physical properties (viscosity, spreadability, adhesiveness, and $\mathrm{pH}$ ) of optimal cream formula, the data for 4 weeks of storage are tested for normality using Shapiro-Wilk. Data that are normally distributed are then analyzed by one-way ANOVA and data that are not normally distributed are analyzed by Kruskal-Wallis. Organoleptic, homogeneity, and cream type test are analyzed descriptively.

\section{RESULTS AND DISCUSSION}

The results of the determination showed that the plants tested were tea (Camellia sinensis L.) based on testing in the Dept. Pharmacy Biology, Faculty of Pharmacy, UGM. The extract produced is in the form of thick dark brown extract, smelled of tea, and thick texture. Maceration of tea powder with a weight of 1000 grams produces a thick extract of 240.4 grams, so that the yield of extract produced is $24.04 \%$. Determination of the drying shrinkage extract was $17.33 \%$ which showed that the number of compounds lost or evaporated during the drying process was $17.33 \%$. Qualitative test extracts are conducted by KLT by looking at the value of Retention factor $(R f)$. The results of the chromatogram indicate the separation into three colored bands under $\mathrm{UV}_{254}$, which is at $R f 0.6,0.8$, and 0.9 . After being sprayed with $\mathrm{FeCl}_{3}$ reactor, a blackish blue ribbon appears with $R f 0.8$. The $R f$ is close to the $R f$ of the EGCG compound in the literature, which is 0.88 (Amarowicz, 2005 in Rustanti et al., 2013). This shows that the extract contains catechin compounds.

The measurement of antioxidant extract activity was initiated by scanning the maximum wavelength $(\lambda)$. The maximum wavelength obtained is $518 \mathrm{~nm}$ with an absorbance value of 0.814 . Positive control used is vitamin C. The measurement of antioxidant activity is indicated by $\mathrm{IC}_{50}$ value, which is the concentration of antioxidant compounds that gives \% inhibition of $50 \%$. Measurements is done three times, and the average $\mathrm{IC}_{50}$ is obtained for extract was $56.35 \mathrm{ppm}$, whereas the average $\mathrm{IC}_{50}$ for vit. $\mathrm{C}$ of $18.53 \mathrm{ppm}$. 
Table IV. Data Determination of Optimal Cream Formula

\begin{tabular}{cccccc}
\hline Criteria & Goal & $\begin{array}{c}\text { Lower } \\
\text { Limit }\end{array}$ & $\begin{array}{c}\text { Upper } \\
\text { Limit }\end{array}$ & Importance & $\begin{array}{c}\text { DX 7 Software } \\
\text { Prediction Value }\end{array}$ \\
\hline Spreadability & Maximize & 13.5 & 18 & $(++++)$ & 18.50 \\
Adhesiveness & In range & 0.8 & 0.95 & $(+++)$ & 0.81 \\
pH & Target to $=4,7$ & 4.5 & 5.063 & $(+++)$ & 4.780 \\
Viscosity & Target to $=2180$ & 2000 & 4000 & $(++++)$ & 2180 \\
\hline
\end{tabular}

Table V. Comparison of the Prediction Value and the Actual Value of the Optimal Formula

\begin{tabular}{ccccc}
\hline Response & Prediction Value & Actual Value & Significance & Interpretation \\
\hline Viscosity & 2170 & 2897.50 & 0.000 & Significantly different \\
Spreadability & 18.50 & 18.44 & 0.150 & Not significantly different \\
Adhesiveness & 0.81 & 0.85 & 0.157 & Not significantly different \\
pH & 4.780 & 4.530 & 0.000 & Significantly different \\
\hline
\end{tabular}

This means vit. $\mathrm{C}$ is more effective as an antioxidant than extract.

Cream optimization with the DX 7 software SLD method produce eight run. The test is conducted by replication three times for each run. Eight run creams show brownish white, smell of tea, soft texture, and visually homogeneous. Data of viscosity, spreadability, adhesiveness, and $\mathrm{pH}$ (Table III). The increase in the composition of Tween 60 will affect to the spreadability and adhesiveness, while the increase in the composition of Span 80 has an effect on viscosity and $\mathrm{pH}$. The presence of Tween 60 which is hydrophilic is binding stronger in the water phase so that it can reduce the consistency of the M/A type cream, and resulting in a high spreadability. Whereas, Span 80 is a lipophilic surfactant and is able to bind stronger to the oil phase, so it will provide high viscosity. The cream type assessment is done by the dilution method. The cream is diluted with aquadest, set as positive or M/A type when dispersed evenly in the aquadest. Six run showed the M/A type cream, while R1 and R5 showed negative test results. The larger composition of Span 80 will produce A/M type cream because Span 80 is a lipophilic surfactant.

From the seven physical properties of creams, which are used for the determination of optimal formula are spreadability, adhesiveness, viscosity, and $\mathrm{pH}$. These four responses are then set to their goal and importance. The optimal formula obtained has a ratio of concentration of Tween 60 greater than Span 80 by considering the lower limit and upper limit of the four responses (Table IV). Prediction value of spreadability in DX 7 software SLD method exceeds the upper limit, which is 18.50 . This can be caused by the degree of importance is quite high, namely $(++++)$. Based on the analysis of DX 7 software SLD method, obtained the optimal formula at concentration of Tween 60 $6.4 \%$ and Span $803.6 \%$ with a value of desirability of 0.934 . Desirability is the desired value and has a range of $0-1$, so if desirability is close to 1 , the recommended formula is more in accordance with the desired criteria. Comparison of concentrations of $6.4 \%$ Tween 60 and $3.6 \%$ Span 80 gives mixed HLB values of 11.1 which are calculated by equation (5). Data determination of the optimal formula (Table IV).

Data of viscosity, spreadability, adhesiveness, and $\mathrm{pH}$ response are tested for normality using Shapiro-Wilk with a confidence level of $95 \%$. The results show data of viscosity, spreadability, adhesiveness, and $\mathrm{pH}$ normally distributed. Statistical analysis is continued with one sample ttest to see the difference between the actual values with SLD predictions. The results of the analysis (Table V). The test results are not significantly different if the significance value was $>0.05$. Spreadability and adhesiveness responses show results that are not significantly different, whereas viscosity and $\mathrm{pH}$ responses show significantly different results. The optimal cream formula was then tested for physical stability at room temperature $\left(28 \pm 2^{\circ} \mathrm{C}\right)$ for 4 weeks including organoleptic, homogeneity, viscosity, spreadability, adhesiveness, $\mathrm{pH}$, and cream type test. Data of viscosity, spreadability, adhesiveness, and $\mathrm{pH}$ during storage (Table VI).

During 4 weeks of storage, the cream does not undergo significant changes, remains brownish white, smells of tea, soft texture, and visually homogeneous. Data of viscosity, spreadability, adhesiveness, and $\mathrm{pH}$ were normally distributed according to the Shapiro-Wilk test with a significance value of $0.054 ; 0.680 ; 0.080$; and 
Table VI. Data of Viscosity, Spreadability, Adhesiveness, and pH of the Optimal Cream Formula during Storage

\begin{tabular}{ccccc}
\hline Week- & Viscosity (mPa.s) & Spreadability $\left(\mathbf{c m}^{2}\right)$ & Adhesiveness (seconds) & pH \\
\hline 0 & $2897,5 \pm 35,94$ & $18,44 \pm 0,06$ & $0,85 \pm 0,05$ & $4.529 \pm 0.002$ \\
1 & $2885,0 \pm 26,46$ & $18,25 \pm 0,08$ & $0,88 \pm 0,03$ & $4.538 \pm 0.004$ \\
2 & $2867,5 \pm 17,08$ & $18,33 \pm 0,13$ & $0,86 \pm 0,03$ & $4.531 \pm 0.006$ \\
3 & $2887,5 \pm 17,08$ & $18,25 \pm 0,09$ & $0,86 \pm 0,06$ & $4.532 \pm 0.003$ \\
4 & $2907,5 \pm 32,02$ & $18,39 \pm 0,05$ & $0,96 \pm 0,08$ & $4.539 \pm 0.003$ \\
\hline
\end{tabular}

0.961. Subsequent tests are parametric with oneway ANOVA. One-way ANOVA test gives significance of $0.335 ; 0.034 ; 0.069$; and 0.005 for viscosity, spreadability, adhesiveness, and $\mathrm{pH}$. Viscosity and adhesiveness show a significance value of $>0.05$, so there is no significant difference, while for spreadability and $\mathrm{pH}$ the significance value is $<0.05$, which means that there is a significant difference for 4 weeks of storage. Therefore, a post-hoc test was conducted in the form of Tukey HSD to see on what week there were significant differences. The results show that the significance value of spreadability is 0.062 . This shows that there is no significant difference in the cream that is stored from week 0 to week 4 . Unlike with $\mathrm{pH}$, there are significant differences when it is stored in weeks 0-1 and weeks to 0-4. Significant values obtained were 0.026 and 0.022 , respectively. The optimal cream formula for $\mathrm{M} / \mathrm{A}$ type after being tested by the dilution method and did not experience cream-type reversal (inversion) for 4 weeks of storage.

\section{CONCLUSION}

From the research above, it can be concluded that the ethanol extract of green tea leaf contains catechin compounds with an $R f$ value of 0.8 and are antioxidant with an $\mathrm{IC}_{50}$ value of 56.35 ppm. The optimal cream formula according to the DX 7 software analysis SLD generate a combination of $6.4 \%$ Tween 60 and $3.6 \%$ Span 80 . The actual value of spreadability and adhesiveness response did not significantly different from the predictive value of the DX 7 software SLD method, but it is significantly different on the viscosity and $\mathrm{pH}$ response. After testing its physical stability for 4 weeks at room temperature $\left(28 \pm 2^{\circ} \mathrm{C}\right)$, organoleptic, homogeneity, adhesiveness, spreadability, viscosity, and cream type did not experience significant changes, but $\mathrm{pH}$ underwent significant changes.

\section{REFERENCES}

Allen, L. V., Popovich, N. G., Ansel, H. C., 2004, Ansel's Pharmaceutical Dosage Forms and
Drug Delivery Systems, Ninth Edition, 398, Lippincott Williams \& Wilkins, Philadelphia. Amarowicz, R., Maryniak, A., \& Shahidi, F., 2005, TLC Separation of Methylated (-)Epigallocatechin-3-Gallate, Czech Journal of Food Science, 23 (1), 36-39 dalam Rustanti, E., Jannah, A., \& Fasya, A. G., 2013, Uji Aktvitas Antibakteri Senyawa Katekin dari Daun Teh (Camellia sinensis L. var assamica) terhadap Bakteri Micrococcus luteus, Alchemy, 2 (2), 138-149.

Bakker, P., Doorne, H. V., Gooskens, V., \& Wieringa, N., 1991, Dermatological Preparations for The Tropics : A Formulary of Dermatological Preparations and Backgrounds of Choices, Production and Dispensing, 147-148, Scienceshop for Medicine, University of Groningen, Netherlands.

Chacko, S. M., Thambi, P. T., Kuttan, R., \& Nishigaki, I., 2010, Beneficial Effects of Green Tea: A Literature Review, BioMed Centrals, 5 (3), 19.

Chen, Y., Wang, M., Rosen, R. T., \& Ho, C. T., 1999, 2,2-Diphenyl-1-picrylhydrazyl RadicalScavenging Active Components from Polygonum multiflorum Thunb., Journal Agriculture Food Chemical, 47, 2226-2228.

Departemen Kesehatan RI, 1979, Farmakope Indonesia, Edisi III, 8, 508-509, 633, Departemen Kesehatan RI, Jakarta.

Departemen Kesehatan RI, 2008, Farmakope Herbal Indonesia, Edisi I, 171, 174-175, Departemen Kesehatan RI, Jakarta.

Mahato, R. I., 2007, Pharmaceutical Dosage Forms and Drug Delivery, 108-111, CRC Press, USA.

Robinson, T., 1995, Kandungan Senyawa Organik Tumbuhan Tinggi, Penerbit ITB, Bandung dalam Rustanti, E., Jannah, A., \& Fasya, A. G., 2013, Uji Aktivitas Antibakteri Senyawa Katekin dari Daun Teh (Camellia sinensis L. var assamica) terhadap Bakteri Micrococcus luteus, Alchemy, 2 (2), 138-149.

Rowe, R. C., Sheskey, P. J., \& Quinn, M. E., 2009, Handbook of Pharmaceutical Excipients, Sixth Edition, 283, 155, 441-445, 474, 483, 
549-552, 675-678, Pharmaceutical Press and American Pharmacists Association 2009, Washington D.C.

Singh, I., Goyal, A., Kumar, S., Nagpal, M., \& Arora, S., 2011, Potential of Novel Drug Delivery
Systems for Herbal Drugs, Indian Journal of Pharmaceutical Education and Research, 45 (3), 225-235.

Soraya, Noni, 2007, Sehat dan Cantik Berkat Teh Hijau, 61-63, Penebar Plus, Jakarta. 